\title{
Correction: Smol, M., et al. Importance of Sustainable Mineral Resource Management in Implementing the Circular Economy (CE) Model and the European Green Deal Strategy. Resource 2020, 9, 55
}

\author{
Marzena Smol ${ }^{1, *(\mathbb{D}}$, Paulina Marcinek ${ }^{2}$, Joanna Duda ${ }^{1}$ and Dominika Szołdrowska ${ }^{2}$ \\ 1 Faculty of Management, AGH University of Science and Technology, Antoniego Gramatyka 10 str., \\ 30-059 Cracow, Poland; aduda@zarz.agh.edu.pl \\ 2 Mineral and Energy Economy Research Institute, Polish Academy of Sciences, Division of Biogenic Raw \\ Materials, Wybickiego 7a str., 31-261 Cracow, Poland; marcinekpa@wp.pl (P.M.); \\ szoldrowska@meeri.pl (D.S.) \\ * Correspondence: smol@meeri.pl; Tel.: +48-695-922-722
}

In the published article [1], the authors realized some errors in the affiliation 1, Figures 3 and 4, and thus wish to replace the file on the webpage of the Resources journal.

1. Please correct the code of affiliation 1 into "30-059".

2. The correct data of Figures 3 and 4 were downloaded from the European Commission website, but when changing the order of raw materials in the Excel file, the corresponding values for the given raw material did not change. This is why the graph was disturbed. This mistake does not affect the content of the article; only one sentence needs to be corrected: "As can be seen from Figure 4, the share of recycled RMs after decommissioning in the EU in 2016 was different for individual resources. The highest values were obtained for lead (75\%), limestone $(58 \%)$, vanadium $(44 \%)$ and copper $(55 \%)$. It is very disturbing that, for many raw materials, these indicators are at zero level (cobalt, lithium, gallium)" in Section 4.1.2. 


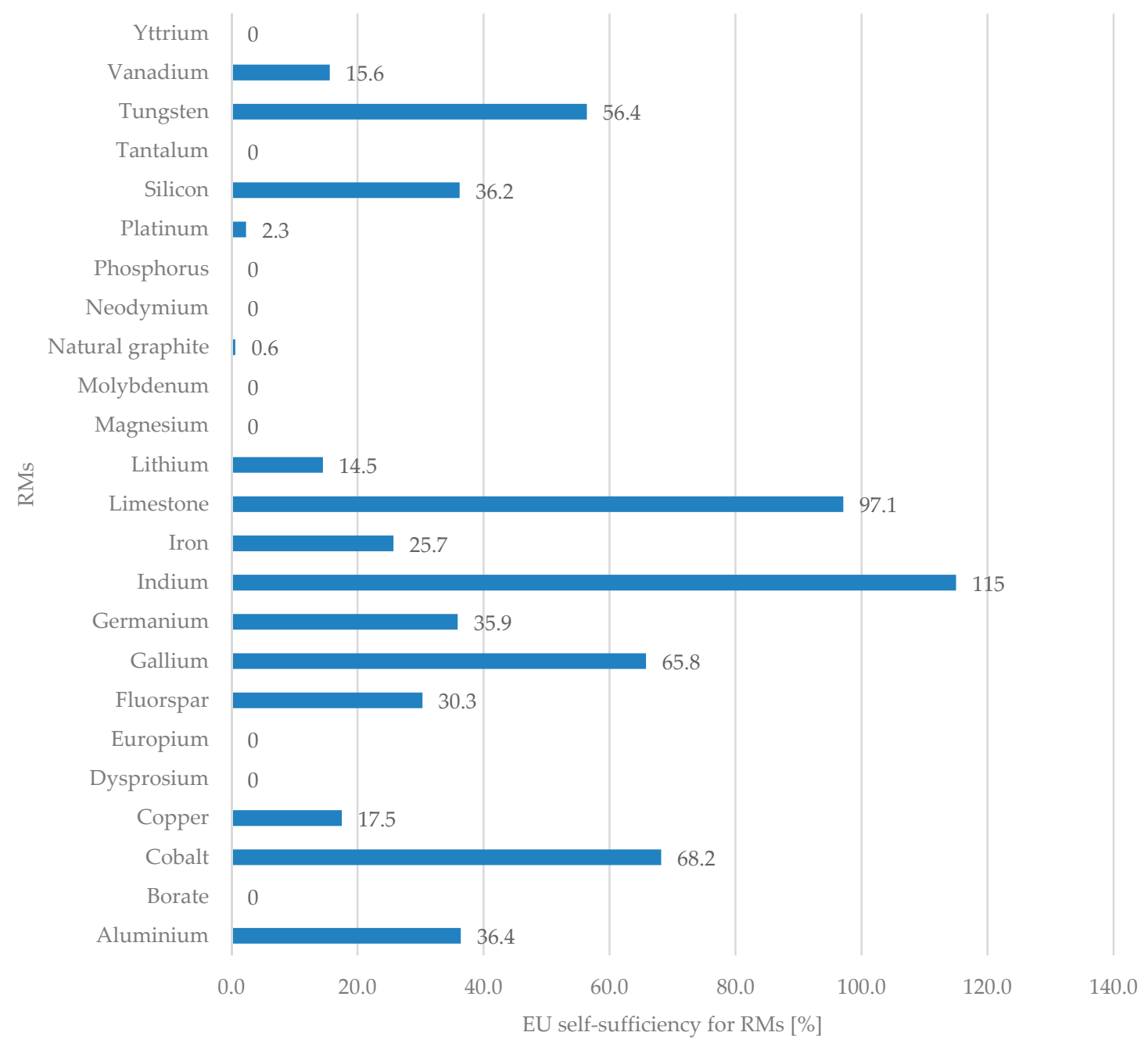

Figure 3. EU self-sufficiency in selected RMs in the EU (28) in 2016 (own insights, based on [11]). 


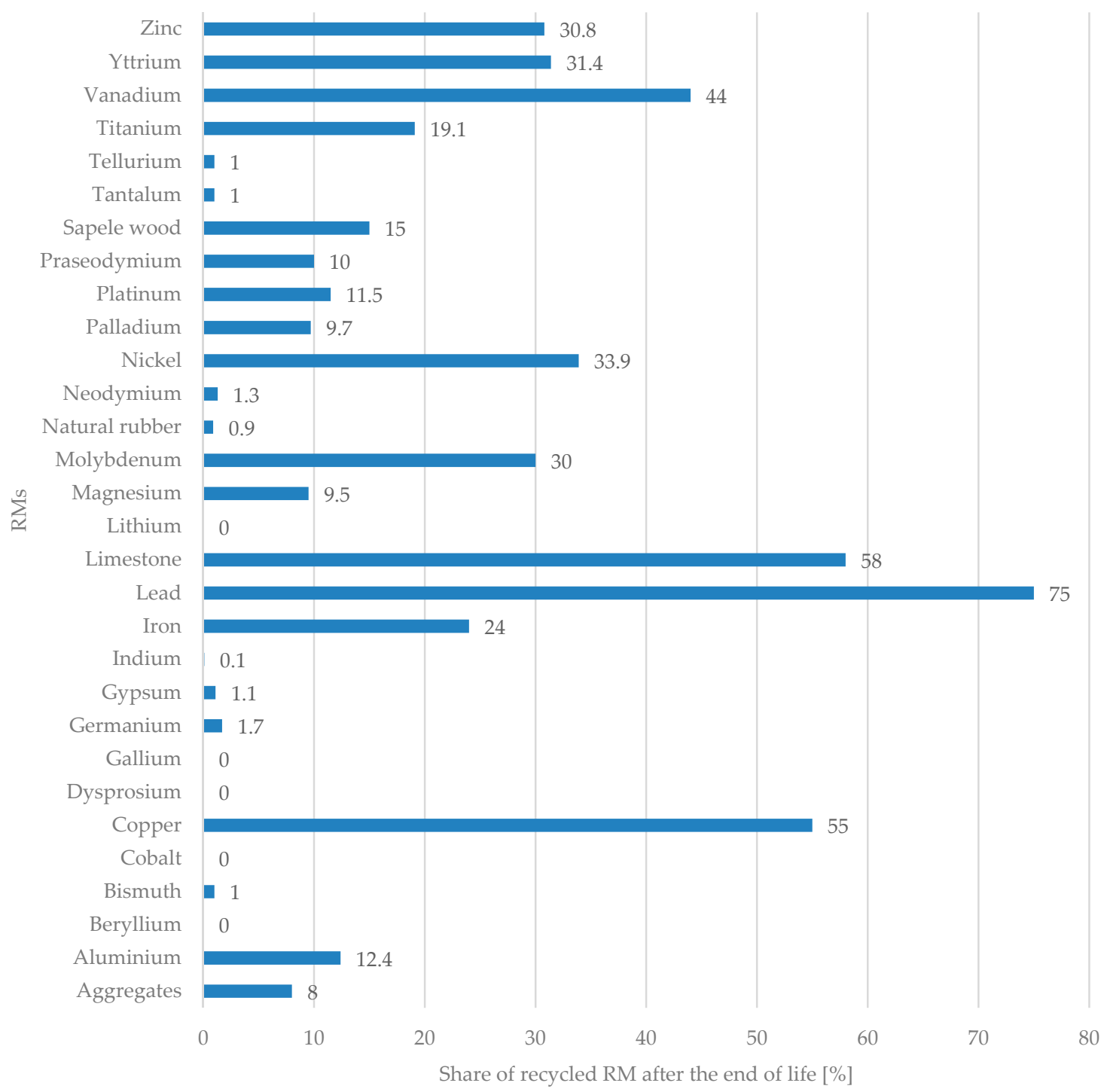

Figure 4. Share of recycled RMs after the end of life in the EU (28) in 2016 (own insights, based on [11]). Aggregates include crushed rock, other sands (not silica), pebbles, gravel, bitumen additives.

The authors would like to apologize for any inconvenience caused to the readers by the change. The change does not affect the scientific results. The manuscript will be updated and the original will remain online on the article webpage, with a reference to this correction.

\section{References}

1. Smol, M.; Marcinek, P.; Duda, J.; Szołdrowska, D. Importance of Sustainable Mineral Resource Management in Implementing the Circular Economy (CE) Model and the European Green Deal Strategy. Resource 2020, 9, 55. [CrossRef]

(C) 2020 by the authors. Licensee MDPI, Basel, Switzerland. This article is an open access article distributed under the terms and conditions of the Creative Commons Attribution (CC BY) license (http://creativecommons.org/licenses/by/4.0/). 